\title{
Driving competition in local markets with Near-Perfect Substitutes: An application on the Spanish Retail Gasoline Market
}

\author{
Jordi Perdiguero ${ }^{1}$ \\ Universitat Autònoma de \\ Barcelona \& GEAP
}

\author{
Joan Ramon Borrell ${ }^{2}$ \\ Universitat de Barcelona, GiM \& \\ IREA
}

\begin{abstract}
Relevant market definition remains a key element in the economic analysis of competition in the gasoline market. However, this is particularly difficult to undertake when competition is local and market power is geographically constrained, as they are in the case of the gasoline market. We analyse how the hypothetical monopolist or Small but Significant Non-Transitory Increase in Prices test performs when defining isochrones based solely on price information and the distance between competitors. We conclude that geographic information systems can be successfully employed in the precise definition of relevant geographic markets in the gasoline retail sector. Their application to the Spanish gasoline market indicates that the relevant geographic market is delineated by a five- to sixminute travel-time isochrone around each station. Localised market power needs to be taken into account when analysing the adverse effects of mergers and entry regulations on gasoline retailing. To drive competition in these local circumstances, markets need to be delineated on the basis of sufficiently small isochrones since only close rivals seem to compete effectively with each other.
\end{abstract}

Keywords: Gasoline retailing, Market definition, Competition, Simulation JEL Codes: L11, L12, L14, R12.

\footnotetext{
${ }^{1}$ Departament d'Economia Aplicada, Universitat Autònoma de Barcelona. Grup de Recerca en Economia Aplicada (GEAP). Edifici B, Campus de la UAB, 08193 Bellaterra, Cerdanyola del Vallès. E-mail: jordi.perdiguero@uab.cat. Telf: +34935811740.

2 Dept. de Política Econòmica. Universitat de Barcelona. Research group of “Governs i Mercats” (GiM), and Institut d'Economia Aplicada (IREA). Universitat de Barcelona. Av. Diagonal 690. 08034 Barcelona. E-mail: jirborrell@,ub.edu
} 


\section{Introduction}

Relevant market definition is a key element in competition policy enforcement in the gasoline market, especially in the retail sector. Although estimation and simulation techniques allow market power to be studied directly without the need for market definition, defining markets and studying their concentration are likely to remain important policy tools for some time (see Brenkers and Verboven, 2006). Indeed, since estimation and simulation techniques remain overly reliant on assumptions regarding both demand and supply side primitives and on the equilibrium condition chosen, they are best used in conjunction with more traditional market definitions and concentration analyses.

A number of studies can be found in the economic literature seeking to approximate the relevant markets for various sectors. Argentesi and Ivaldi (2007) for the printed media industry and Ivaldi and Lörincz (2011) for computer servers are two examples. However, in the case of the gasoline market, studies can be found that analyze the relevant geographic market only for the wholesale sector. Spiller and Huang (1986) show how refineries in the Northeastern United States compete in different relevant markets and how the more isolated refineries are able to exercise market power. Pinkse et al (2002) also analyze the wholesale gasoline market in the US, but employ a semiparametric estimator. They find that there is no global market for the whole country, but rather that every refinery competes with its neighbours. As such, the relevant geographic market is essentially local. Audy and Erutku (2005) apply different price tests in defining relevant markets in the wholesale gasoline sector of Canada. They report markets larger than cities but no bigger than the whole country. In fact, their results show the existence of more than two markets within Canada.

Thus, although there is considerable empirical evidence of the size of the gasoline wholesale market, no empirical analyses have sought to determine the size of relevant geographic markets in the retail sector. Economic intuition suggests that such markets may be local, but we know nothing about their size. The aim of this paper, therefore, is to measure the size of these markets. Having done so, we also propose economic policy measures that might improve the level of competition within them.

To measure the size of the relevant geographic markets in the gasoline retailing sector we have applied the Small but Significant Non-Transitory Increase in Prices test (SSNIP test). This test is used by the competition authorities to define markets and makes the economics 
of market definition more explicit. The US and EU merger guidelines currently use the SSNIP test to define markets. We have to take into account that the SSNIP test is only valid if firms compete in the market, and fails if firms have market power. This is known as the "cellophane fallacy" from the Du Pont case in 1956 (Sharma, 2011). The test measures whether a monopolist would be interested in introducing a permanent and significant price increase (of at least 5\%) after acquiring rival firms. If the monopolist was interested, the products or outlets analyzed could be considered as lying within the same relevant market. Our aim is to identify the limits within which rivalry has beneficial effects for consumers.

In this paper, we analyse how the SSNIP test performs when defining markets based on price information and on the distance between retail outlets. The competition between petrol stations can be considered a paradigmatic case of competition in local markets, presenting common characteristics of competition between retail outlets. There is growing interest in defining local markets on the basis of isochrones in order to examine retail rivalry (Office of Fair Trading 2005, Competition Commission 2003 and Baker 1999). The key issue in the study of local competition is determining how large these isochrones need to be in order to drive competitors in.

Here, we conclude that geographic information systems can be successfully employed in the precise definition of relevant geographic markets. Applying the test to petrol stations, we find that relatively small isochrones drive enough competitors in and that local market power is greater than it is usually considered to be in cases of competition and retail regulation. Results show that the entry of new operators from different existing brands within a five to six-minute travel-time isochrone can significantly reduce the price. In relevant markets with more than one same brand station, the equilibrium price would be lower if one of the operators changed its flag, thereby increasing the number of competitors. Thus, removing the entry barriers that limit the number of operators and introducing policies to facilitate the change of flag can increase the level of competition and reduce the price equilibrium.

Following on from this introduction, section 2 shows the theoretical relationship between the number of participants in the market and price equilibrium. Section 3 describes the data used here in applying this methodology to the case of competition between petrol stations occupying roadside locations. Section 4 offers the results of the application and section 5 concludes. 


\section{Number of outlets and price equilibrium}

In this section we show that equilibrium prices in each relevant market depends directly on the number of sellers (petrol stations in our data), and whether those sellers belong to the same brand chain or to a rival brand chain. By contrast, we will show that equilibrium prices depend only indirectly on market size, as any shift in market size encourages more entry.

In the petrol station industry, stations may be independent rivals or belong to a chain that resells gas provided by a major petrol brand or flag under an exclusivity contract. Although contract differ widely across countries, we will look closely at the case in which petrol stations under contract have no room to modify resell prices set by the brand owner for all stations using any resell price maintenance mechanism.

We generalize the proposals by Gampbell and Hopenhayn (2005) that outline how market size has only an indirect impact on equilibrium pricing through its direct impact on the number of sellers.

For distinguishing the impact of market size on entry, and then the effect of entry on pricing, we will model the entry game and the demand system using a multinomial logit model assuming that we have a limited number of spots available for entry in any given relevant market: let us say that there are potential locations which we will name by sub index $j=1,2, \ldots, J$.

Berry (1994) and Berry, Levinshon \& Pakes (1995) outlined the fundamentals of such discrete-choice models for analysing differentiated product markets with heterogeneous consumers. Brenkers and Verboven (2006), Argentesi and Ivaldi (2007) and Ivaldi and Lörincz (2011) discuss how to use them for defining relevant markets in antitrust cases. As discussed by Anderson, de Palma and Thisse (1992), multinomial logit demand systems fit perfectly on the theory literature analysing oligopoly models and outline similar propositions regarding the effects of competition on pricing behaviour and product variety/location in equilibrium than other continuous models with homogeneous consumer demands. 
First, we will look at the case in which there are no brand chains. All entrants are independent or have different flags to each other, and each firm has only one station (single-station firms) in the relevant market. Let $\chi_{j}=\{0,1\}$ index whether there is entry in location $j$ or not: a station is open to the public in location $j\left(\chi_{j}=1\right)$, or there is not station open to the public in such location $j\left(\chi_{j}=0\right)$. And, let the number of entrants be just the sum of such spot specific index: $N^{r}=\sum_{j=1}^{J} \chi_{j}$. Super index $r$ indicates that we focus first on the case in which all entrants are rivals, whether independent station or different brand stations.

There will be entry in any spot whenever profits are non-negative, where profits in equilibrium are equal to the difference between prices $\left(p_{j}\right)$ and marginal $\operatorname{costs}\left(c_{j}\right)$ at each spot, times the quantity sold at each spot $\left(q_{j}=s_{j} M\right)$, minus the fixed costs of entering at each $\operatorname{spot}\left(f_{j}\right)$.

Each station total sales at the equilibrium are $q_{j}=s_{j} M$. Total sales depend on market size $(M)$, the number of potential consumers at that relevant market. Total sales also depend on the shares of each and every actual station open in that market $\left(s_{j}\right)$ for $j=1,2, \ldots, J$ at the potential locations; $j=0$ is the outside good, and $s_{0}$ the share of potential consumers that finally are opting for the outside good, not consuming in any of the stations open to the public. For the sake of simplicity, we assume that consumers are heterogeneous with respect to their preference for consuming in one or other location, but they are homogeneous with respect their fuel needs just pumping a fixed and common amount of petrol when visiting the station.

$$
\begin{gathered}
\chi_{l j}=1 \Leftrightarrow E\left(\pi_{j}\right) \geq 0 \\
\pi_{j}=\left(p_{j}-c_{j}\right) s_{j} M-f_{j}
\end{gathered}
$$

Assuming that each and every potential consumer in the relevant market, as in Bajari et al. (2010), form their expectations to find a shop in any of the $J$ potential spots, according to the public information regarding profit functions, the market share at each and every location can be expressed by the multinomial logit probability function whenever consumer have utility functions like the following, in which there is a common mean utility that they obtain from consuming at each location $\left(\delta_{j}\right)$, a common linear mean disutility 
from paying the per unit price $\left(-\alpha p_{j}\right)$, and an idiosyncratic consumer specific taste for each location $\left(\epsilon_{i j}\right)$.

As consumers will chose the option that maximize their expected utility among all the $j=0,1,2, \ldots, J$ options (including the outside good), the idiosyncratic consumer specific tastes distributes as an extreme value shock, and market shares equal the multinomial logit probabilities as follows:

$$
\begin{aligned}
& U_{i j}=\delta_{j}-\alpha p_{j}+\epsilon_{i j} \\
& s_{j}=\frac{\exp \left(\delta_{j}-\alpha p_{j}\right)}{1+\Sigma_{j=1}^{J} x_{j} \exp \left(\delta_{j}-\alpha p_{j}\right)}
\end{aligned}
$$

Finally, if entering firms maximize profits with respect to the prices they charge at their location post-entry, the system of equilibrium prices for single-station firms in the relevant market looks as follows, given that, in the multinomial logit demand system, the derivative of the market share with respect to the price is $\frac{\partial s_{j}}{\partial p_{j}}=-\alpha s_{j}\left(1-s_{j}\right)$ :

$$
\begin{aligned}
& p_{j}=c_{j}+\frac{s_{j}}{\left|\frac{\partial s_{j}}{\partial p_{j}}\right|} \\
& p_{j}=c_{j}+\frac{1}{\alpha\left(1-s_{j}\right)}
\end{aligned}
$$

Post-entry equilibrium prices for the entrants are equal to marginal costs plus the inverse of the semi-elasticity of residual demand at each and every location.

In this set up, it is clear cut that equilibrium sales at each potential location depend on the number of rival entrants as $N^{r}=\sum_{j=1}^{J} \chi_{j}$ as the index $\chi_{j}=\{0,1\}$ is entering the market share denominator for all and every location that has finally an entrant at the equilibrium.

Any increase in market size $(M)$ will encourage entry through the profit function in equations (1) and (2) as long as equilibrium prices are larger than marginal costs, $p_{j}>c_{j}$, and fixed costs are not too large $\left(f_{j}\right): \frac{\partial \pi_{j}}{\partial M}>0$. 
And, equilibrium market shares at each location are decreasing with market size, as the increasing probability of having rivals when market size grows large, $\frac{\partial_{X_{j}}}{\partial M}>0$, increases the second term in the denominator in the market share function in equation (4), and therefore, decreases equilibrium market shares: $\frac{\partial s_{j}}{\partial M}<0$.

As market share decreases with entry of rivals driven by the larger market size, equilibrium prices decrease with the entry of rivals driven by market size grow, $\frac{\partial p_{j}}{\partial N^{T}}<0$, as the elasticity of residual demand increases (the inverse of such elasticity decreases) in (5), and particularly in our simple but general utility equation set up outlined in this section, the denominator of the second term of the pricing function in (6) increases.

This price drop by entry of rivals is driven by the fact that more entrants in the market reduce product differentiation among the outlets. So, firms cannot charge so large prices as consumers have more alternatives, and the market share of each competitor is smaller with more rival entrants in the market. Consumers chose the outlets closer to their idiosyncratic preferences. They do not have to move away to other more "distant outlets." To attract them, all stores have to reduce pricing.

Let us now, analyse the other extreme case. Let us assume that there is one incumbent brand firm that pre-empts entry from rivals by opening own brand stations at all the other spots available whenever profits are positive under the new stations ownership structure. So, we can then analyse how market size drives more own brand stores by the same firm in a completely free entry market. By so doing, we will analyse the impact of market size on own-firm multi-store number of entrants, $N^{\circ}=\sum_{j=1}^{I} \chi_{j}$, and pricing. Super index $o$ indicates that we focus now on the case in which all entrants are under contract of the same major petrol firm and use the same flag or brand at the retail market.

In this case, all the above equations remain but the pricing equation system for any maximizing profit chain that monopolizes a market by pre-empting entry of rivals and changing the full monopoly price looks like the following:

$$
p_{j}=c_{j}+\frac{s_{j}}{\left|\frac{\partial s_{j}}{\partial p_{j}}\right|}+\sum_{g=1}^{G}\left(p_{g}-c_{g}\right) \frac{\frac{\partial s_{g}}{\partial p_{j}}}{\left|\frac{\partial s_{j}}{\partial p_{j}}\right|}
$$


Equilibrium price at each spot $j$ is equal to marginal costs plus the inverse of the own price elasticity of residual demand at that spot, and also plus a term that takes into the price cost margins in other spots (sub indexed by the letter $g$ ) times how much of the market share lost at each spot $j$ by a price increase at such spot $j$ is captured by increasing market shares in other spots $g=1,2, \ldots, G$.

$$
p_{j}=c_{j}+\frac{1}{\alpha\left(1-s_{j}\right)}+\sum_{g=1}^{G}\left(p_{g}-c_{g}\right) \frac{s_{g}}{\left(1-s_{j}\right)}
$$

As in equations (5) and (6), in equations (7) and (8), the second term of the pricing equation decreases with market size as market shares of incumbent decreases with entrants. This is the cannibalization effect of the new stations of the same brand with respect to the other stations.

However, the new third term (the one including the sum of the cross price derivative of market shares) increases with respect to market size, as more entrants allow the chain to recoup consumers that were previously buying in outlet $j$ by having them diverted toward stores $g=1,2, \ldots, G$ as consumers in any other station of the same brand (diversion effect). Additionally, with new entrants, some consumers that were opting for the outside good $\left(s_{0}\right)$, may finally buy in the new stations (the market expansion effect in differentiated product markets).

The impact of the entry of more stations of the same brand on equilibrium pricing depends on the magnitude of these two balancing effects. Second term or cannibalization effect is large when differentiation among stores is low.

The third term has two components: 1) one is the diversion effect that compensates the cannibalization effect. the new stations attract consumers previously going to the other same brand incumbent stations; 2) the other is the market expansion effect, the new stations may attract consumers that before were opting for the outside good, as stations are located closer to all consumers "idiosyncratic" tastes. This is always positive as it is a new summand that gets larger and larger with more entry.

As long as the diversion and market expansion effects more than compensate the cannibalization effect, entry of more stores of the same chain has a positive impact on pricing. So, with the increase in market size, more own brand multi-station pre-empting entry drives larger pricing: $\frac{\partial p_{j}}{\partial N^{0}}>0$. 
The shape of the effect however is not clear; it may be non-linearly convex as all those effects turn to be smaller at the margin as the market size grows and the number of entrants increase. Once all the available spots are occupy, market sixe increase has no longer any effect on equilibrium pricing. The effect is exhausted.

For showing the effect of market size expansion in single-station, multi-station and mixed single and multi-station competition, we have simulated average pricing for a given set of parameters of the outlined model of simultaneous entry, market share and pricing system of equations in table 1 for a relevant market with 30 potential locations.

We assume for the simulation that locations have normalized unit constant mean attractiveness for potential consumers $\left(\delta_{j}=1 \quad\right.$ for $\left.j=1,2, \ldots, 30\right)$, being the mean utility from consuming the outside good normalized to be zero as usual, $\delta_{0}=0$.

We have assumed that marginal costs and fixed costs are all equal for all potential locations. This allows us to focus our attention on the impact of market size on entry, and also to show the impact of entry driven by this increase in market size on equilibrium pricing.

Table 1 shows the number of entrants and pricing in different market equilibria combining one chain of petrol stations competing with a bunch of independent stations in which no other independent entrant may obtain non-negative profits, nor the opening of other own brand station by the chain increases its profits. We can see that pricing is larger in markets where one firm have more own brand stations (the highest price is in a market with 5 own brand stations plus 5 rivals with a price of 1.48), than in markets with a low level of own brand stations and a lot of rivals (the lowest price is in a market with 2 stations of the same brand and 13 single brand stations).

Other characteristic that show table 1 is the positive relationship between market size and number of petrol stations. ${ }^{3}$ When the market size increase the number of petrol stations that enter in the market is greater.

\footnotetext{
3 The effect of any difference in resident income across market is equivalent to the effect of a market expansion: it would drive higher prices and markups up to the point in which it would drive more entrants into the market (see table 1).
} 
Table 1

Simulation of the effect of market size and entry on pricing

\begin{tabular}{|c|c|c|c|c|}
\hline $\begin{array}{l}\text { Market size } \\
(\boldsymbol{M})\end{array}$ & $\begin{array}{c}\text { Own Store } \\
\left(N^{o}\right)\end{array}$ & Rivals $\left(\boldsymbol{N}^{r}\right)$ & $\begin{array}{c}\text { Entrants } \\
\left(N=N^{r}+N^{o}\right)\end{array}$ & Average Price \\
\hline 1000 & 4 & 5 & 9 & 1,43 \\
\hline 1100 & 5 & 5 & 10 & 1,48 \\
\hline 1200 & 4 & 7 & 11 & 1,35 \\
\hline 1300 & 5 & 5 & 10 & 1,45 \\
\hline 1400 & 3 & 9 & 12 & 1,25 \\
\hline 1500 & 4 & 9 & 13 & 1,36 \\
\hline 1600 & 4 & 10 & 14 & 1,29 \\
\hline 1700 & 2 & 13 & 15 & 1,13 \\
\hline 1700 & 6 & 10 & 16 & 1,38 \\
\hline 1800 & 5 & 11 & 16 & 1,32 \\
\hline 1900 & 5 & 12 & 17 & 1,36 \\
\hline 2000 & 8 & 9 & 17 & 1,46 \\
\hline 2100 & 6 & 13 & 19 & 1,33 \\
\hline 2200 & 8 & 13 & 21 & 1,40 \\
\hline 2300 & 7 & 14 & 21 & 1,35 \\
\hline 2400 & 7 & 15 & 22 & 1,34 \\
\hline
\end{tabular}

$\alpha=1$.

$\delta_{0}=0 ; \delta_{j}=1 \quad$ for $\quad j=1,2, \ldots, 30 . c_{j}=0$ for $j=1,2, \ldots, 14$.

$f_{j}=100$ for $j=1,2, \ldots, 14$.

Source: Author's simulations.

Using data from the above table we have estimated an econometric regression and, as shown in Table 2, results confirm the effects of the composition of the market on prices. The number of competitors has a negative and significant effect, while the number of own brand petrol stations has a positive effect. As regards the squared variables, the number of competitors is not significant, while the number of own brand petrol stations is negative and significant, indicating that the relationship between the number of own brand petrol stations and price may be nonlinearly convex. 
Table 2

Econometric estimation with simulation data

\begin{tabular}{lr}
\hline Constant & $1.276^{* * *}$ \\
& $(0.074)$ \\
N_rival(.) & $-0.034^{* * *}$ \\
& $(0.010)$ \\
N_rival(.) ${ }^{2}$ & 0.001 \\
& $(0.000)$ \\
N_own(.) & $0.093^{* * *}$ \\
& $(0.016)$ \\
N_own(.) ${ }^{2}$ & $-0.005^{* * *}$ \\
& $(0.002)$ \\
\hline F(4,14) & $313.73^{* * *}$ \\
& $(0.000)$ \\
$\mathbf{R}^{2}$ & 0.9545 \\
\hline
\end{tabular}

Robust Standard Errors within parentheses (* 10\%, ** 5\%, *** 1\%).

\section{Data}

The SSNIP test is demanding in its data requirements. Not only do we need to know the price of a largely homogeneous product sold at different outlets, but we also need information about the geographic location of each of these outlets, the distance in time between them, and which outlets are under the ownership of which competing firms.

Here, we use data from all 590 petrol stations with a roadside location (excluding motorway stations and those occupying a city or suburban location) in Catalonia, a region in the northeast of Spain with around 7,5 million inhabitants that occupies an area similar to that of Belgium or Massachusetts. Regular gasoline prices without taxes ${ }^{4}$ (unleaded 95 octane) sold at each outlet were obtained for the week of $31^{\text {st }}$ July 2005 from the Ministry of Industry's web page. All petrol stations were geographically located, and all distances (in terms of car journey time) from one petrol station to all other stations were computed

\footnotetext{
${ }^{4}$ Results not change if we take into account price with taxes because the taxation is the same for all the petrol
} stations. 
(348,100 time distances in total). We identified the petrol station brand: that is, the name of the gasoline firm owning the station or serving it via an exclusivity contract based on information available at the firms' websites. All petrol stations not branded by one of the major firms are listed as being independent. We also obtained traffic density figures in the vicinity of each petrol station and population data in the neighbourhood of each station from the Statistical Institute of Catalonia (Idescat).

Table 3 shows the distribution of petrol stations by brand and the mean and standard deviation of prices for each firm.

Table 3. Number of roadside petrol stations and average prices by firm

\begin{tabular}{lccc}
\hline Brand & $\begin{array}{c}\text { Number of petrol } \\
\text { stations }\end{array}$ & $\begin{array}{c}\text { Mean Price } \\
\text { (cents Euro) }\end{array}$ & $\begin{array}{c}\text { Standard } \\
\text { deviation of } \\
\text { prices }\end{array}$ \\
\hline Repsol & 258 & 46.962 & 0.762 \\
Cepsa & 84 & 46.511 & 0.908 \\
Galp & 42 & 46.646 & 1.183 \\
Petrocat & 35 & 47.031 & 0.534 \\
BP & 29 & 46.747 & 0.600 \\
Shell & 14 & 46.313 & 1.683 \\
Meroil & 14 & 46.159 & 1.201 \\
Tamoil & 10 & 46.936 & 1.217 \\
Saras & 7 & 46.295 & 0.251 \\
Petromiraller & 5 & 46.962 & 0.308 \\
ERG & 4 & 45.962 & 0.896 \\
Supermarkets & 3 & 41.249 & 2.215 \\
Independent & 85 & 46.324 & 1.301 \\
Total & 590 & 46.704 & 1.054 \\
\hline Souce: Bas & & & \\
\hline
\end{tabular}

Source: Based on information from the web pages of the Ministry of Industry and the major petrol firms.

Based on these data, we computed a vector for each petrol station containing the number of rival brand outlets with which each competes in an isochrone (car travel-time) ranging from 1 to 15 minutes. We assume there to be no intra-brand competition, but we allow competition between independent petrol stations (i.e., between any outlets not owned or served by one of the major petrol players). The extent to which stations operating under an 
exclusivity contract signed with one of the big petrol firms compete with each other is not clear. According to Contín et al (1998), most petrol stations under contract will earn a fixed percentage on final prices as set by the provider. Therefore, there is little or no room for outlets to modify the prices set by the brand owner in any coordinated fashion.

Table 4 shows the total number of petrol stations in our database with rivals in each successive isochrone fixed from 1 to 15 minutes in a radius around each petrol station, and the mean number of rivals in each isochrone. The table also shows the number of markets in which no rival outlets are found within a given isochrone, and in these instances the number of markets in which there is more than one same brand outlet. As we can see in the table 2, up until isochrones of three minutes of distance time, the mean number of rivals is greater than the mean number of own brand outlets. It seems like own brand petrol station tend to be close but not too close when the market boundaries is at least greater than three minutes of travel distance 
Table 4. Market structure within isochrones

(distance time in minutes)

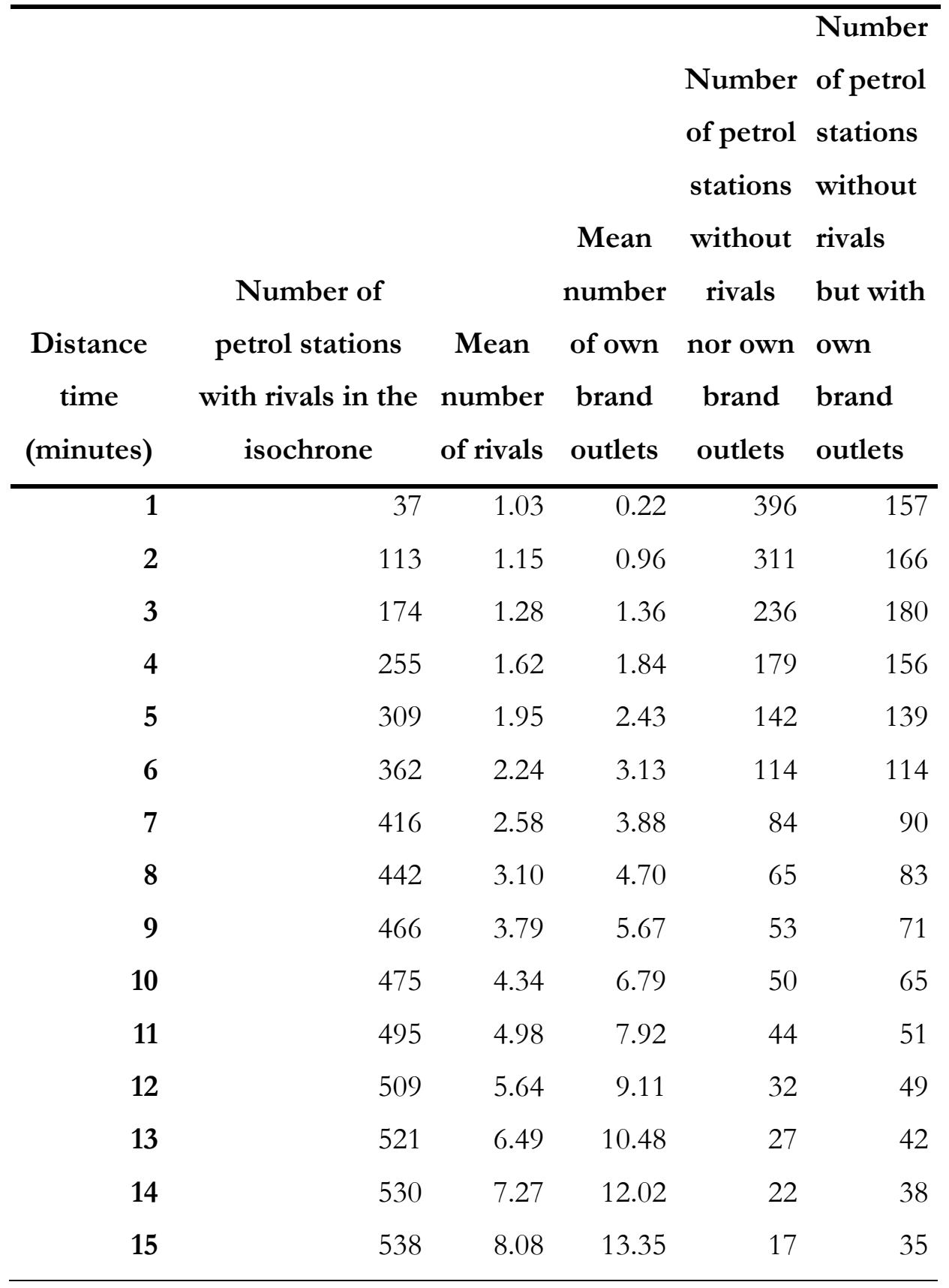




\section{Results}

As suggested by the model in section 2 , we estimate the impact of entry by rival brand outlets and by own brand outlets on equilibrium prices at each station. We estimated 15 linear regressions to infer the impact of rivalry on equilibrium prices, which is the coefficient $\alpha_{1}$ in the following equation when defining the relevant market from 1 to 15 minute isochrones:

$$
P_{i}=\alpha_{0}+\alpha_{1} N_{i}^{r}+\alpha_{2} N_{i}^{o}+\alpha_{3} N_{i}^{o 2}+\varepsilon_{i}
$$

where $i=1,2, \ldots, 590$ petrol stations, $N_{i}^{r}$ is the number of rival outlets within the 1 - to 15 minute isochrone, and $N_{i}^{o}, N_{i}^{o 2}$ is the number of petrol stations of the brand of outlet $i$ within the isochrones and its square ${ }^{5}$.

As discussed in section 2, the number of rivals and the number of same brand outlets within the isochrone is not exogenous because, in equilibrium, we expect the number of outlets to depend on market size (potential demand in terms of population and traffic flows) and on the number and variety of brands that are already in the market. We estimate the previous equations using not only OLS but also instrumental variables (IV) techniques using the brand of the nearest rivals, the population of the area in which each petrol station is sited and the Mean Daily Intensity (MDI) of the traffic on the road served as instruments. The population was calculated based on census data for the location of each service station and its surroundings, i.e., the number of people living in a radius extending 1 to 15 minutes around the station. In this way, we assigned the population residing in the station's defined market. The traffic intensity figure assigned to each service station was that recorded at a measurement point nearest to the station. ${ }^{6}$

Table 5 shows the IV results. In the specification, standard errors are robust to heteroskedasticity and the correlation clustered geographically around roads. The error

\footnotetext{
${ }^{5}$ Results include the variable number of rivals squared are in the annex 1 . We can see like results are less precise because there is not a large heterogeneity of number of rivals between petrol stations, so the two variables are very similar.

${ }^{6}$ The results are not significantly altered if we consider that traffic as a demand factor can also influence the equilibrium price. If there are barriers to entry that deter new operators when the traffic increases, then traffic may explain prices rather than the number of entrants.
} 
term are clustered by road to take into account the possibility that the variance is different among roads but equal inside the same road. 


\section{Table 5. IV estimates}

$P_{i}=\alpha_{0}+\alpha_{1} N_{i}^{r}+\alpha_{2} N_{i}^{o}+\alpha_{3} N_{i}^{o 2}+\varepsilon_{i}$

\section{Observations: $\mathbf{5 9 0}$}

Endogenous regressor: $N_{i}^{r}, N_{i}^{o}, N_{i}^{o 2}$. Instruments: population, dummy brand of closest rival, MDI.

\begin{tabular}{|c|c|c|c|c|c|c|c|c|}
\hline & 1 minute & 2 minutes & 3 minutes & 4 minutes & 5 minutes & 6 minutes & 7 minutes & 8 minutes \\
\hline \multirow[t]{2}{*}{ Constant } & $46.243^{* * *}$ & $46.040 * * *$ & $46.323 * * *$ & $46.944 * * *$ & $46.216^{* * *}$ & $45.946^{* * *}$ & $46.039 * * *$ & $45.915^{* * *}$ \\
\hline & $(0.396)$ & $(0.437)$ & $(0.312)$ & $(0.510)$ & $(0.943)$ & $(0.749)$ & $(0.466)$ & $(0.463)$ \\
\hline \multirow[t]{2}{*}{ N_rival(.) } & 3.333 & -4.009 & -1.418 & 0.199 & $-1.240 *$ & $-1.017 * *$ & $-0.737 * * *$ & $-0.609 * * *$ \\
\hline & (2.041) & $(2.940)$ & $(1.059)$ & $(1.068)$ & $(0.733)$ & $(0.456)$ & $(0.291)$ & $(0.243)$ \\
\hline \multirow[t]{2}{*}{ N_own(.) } & $7.227 *$ & 3.294 & 0.256 & -1.516 & 0.733 & 1.038 & 0.800 & 0.767 \\
\hline & $(3.768)$ & (3.114) & $(1.370)$ & (1.688) & $(1.690)$ & $(0.979)$ & $(0.587)$ & $(0.506)$ \\
\hline \multirow[t]{2}{*}{ N_own $(.)^{2}$} & -5.952 & -0.269 & 0.393 & 0.446 & 0.076 & -0.027 & -0.028 & -0.029 \\
\hline & $(4.341)$ & $(1.225)$ & $(0.473)$ & $(0.288)$ & $(0.245)$ & $(0.114)$ & $(0.065)$ & $(0.046)$ \\
\hline \multirow[t]{2}{*}{$\mathrm{F}(3,172)$} & $3.30 * *$ & 0.88 & $2.27^{*}$ & $3.34 * *$ & $2.64^{*}$ & $3.20 * *$ & $3.94 * * *$ & $5.26 * * *$ \\
\hline & $(0.0217)$ & $(0.4543)$ & $(0.0817)$ & $(0.0206)$ & $(0.0509)$ & $(0.0246)$ & $(0.0095)$ & $(0.0017)$ \\
\hline Overidentification & 4.765 & 2.733 & 7.150 & $9.370^{*}$ & 2.925 & 4.052 & 3.535 & 4.575 \\
\hline Hansen J Statistic & $(0.3122)$ & $(0.6035)$ & $(0.1282)$ & $(0.0525)$ & $(0.5705)$ & $(0.3991)$ & $(0.4726)$ & $(0.3338)$ \\
\hline $\begin{array}{l}\text { Cragg-Donald Wald F } \\
\text { statistic }\end{array}$ & 0.640 & \multicolumn{6}{|c|}{ statistic } & 0.777 \\
\hline F test excluded & $3.68^{* * *}$ & $4.49 * * *$ & $7.53^{* * *}$ & $9.55^{* * *}$ & $8.00^{* * *}$ & $8.43^{* * *}$ & $10.53^{* * *}$ & $10.89 * * *$ \\
\hline \multirow[t]{3}{*}{ instruments } & $(0.0010)$ & $(0.0001)$ & $(0.0000)$ & $(0.0000)$ & $(0.0000)$ & $(0.0000)$ & $(0.0000)$ & $(0.0000)$ \\
\hline & $2.53 * *$ & $3.74 * * *$ & $7.98 * * *$ & $8.24 * * *$ & $7.90 * * *$ & $7.05^{* * *}$ & $7.68 * * *$ & $7.62 * * *$ \\
\hline & $(0.0168)$ & $(0.0009)$ & $(0.0000)$ & $(0.0000)$ & $(0.0000)$ & $(0.0000)$ & $(0.0000)$ & $(0.0000)$ \\
\hline
\end{tabular}




\begin{tabular}{rrrrrrrr}
$2.02^{*}$ & $2.75^{* * *}$ & $7.29^{* * *}$ & $5.56^{* * *}$ & $6.22^{* * *}$ & $5.79 * * *$ & $5.33^{* * *}$ & $5.76^{* * *}$ \\
$(0.0547)$ & $(0.0098)$ & $(0.0000)$ & $(0.0000)$ & $(0.0000)$ & $(0.0000)$ & $(0.0000)$ & $(0.0000)$ \\
\hline
\end{tabular}




\begin{tabular}{|c|c|c|c|c|c|c|c|}
\hline & 9 minutes & 10 minutes & 11 minutes & 12 minutes & 13 minutes & 14 minutes & 15 minutes \\
\hline \multirow[t]{2}{*}{ Constant } & $45.671^{* * *}$ & $45.767 * * *$ & $45.628^{* * *}$ & $45.465^{* * *}$ & $45.292^{* * *}$ & $45.500^{* * *}$ & $45.456^{* * *}$ \\
\hline & $(0.464)$ & $(0.568)$ & $(0.589)$ & $(0.579)$ & $(0.766)$ & $(0.666)$ & $(0.676)$ \\
\hline \multirow[t]{2}{*}{ N_rival(.) } & $-0.364 * * *$ & $-0.327 * * *$ & $-0.294 * * *$ & $-0.257 * * *$ & $-0.256 * * *$ & $-0.203^{* * *}$ & $-0.176^{* * *}$ \\
\hline & $(0.115)$ & $(0.093)$ & $(0.075)$ & $(0.074)$ & $(0.069)$ & $(0.051)$ & $(0.044)$ \\
\hline \multirow[t]{2}{*}{ N_own(.) } & $0.689 * * *$ & $0.553 * *$ & $0.521^{* * *}$ & $0.494 * * *$ & $0.505^{* * *}$ & $0.383^{* * *}$ & $0.330^{* * *}$ \\
\hline & $(0.262)$ & $(0.237)$ & $(0.203)$ & $(0.156)$ & $(0.192)$ & $(0.134)$ & $(0.119)$ \\
\hline \multirow[t]{2}{*}{ N_own $(.)^{2}$} & -0.031 & -0.021 & -0.017 & $-0.015^{* *}$ & $-0.014 *$ & $-0.009 * *$ & $-0.007 * *$ \\
\hline & $(0.021)$ & $(0.016)$ & $(0.012)$ & $(0.007)$ & $(0.007)$ & $(0.004)$ & $(0.003)$ \\
\hline \multirow[t]{2}{*}{$\mathrm{F}(3,172)$} & $8.18^{* * *}$ & $7.59 * * *$ & $8.42^{* * *}$ & $7.64 * * *$ & $5.6^{* * *}$ & $6.42^{* * *}$ & $6.18^{* * *}$ \\
\hline & $(0.0000)$ & $(0.0001)$ & $(0.0000)$ & $(0.0001)$ & $(0.0011)$ & $(0.0004)$ & $(0.0005)$ \\
\hline Overidentification & $7.999 *$ & $9.210^{*}$ & 7.438 & 6.849 & $8.120^{*}$ & $8.390 *$ & 6.930 \\
\hline Hansen J Statistic & $(0.0916)$ & $(0.0561)$ & $(0.1145)$ & $(0.1441)$ & $(0.0873)$ & $(0.0783)$ & $(0.1396)$ \\
\hline Cragg-Donald Wald & 1.181 & 1.443 & 1.486 & 1.990 & 1.722 & 2.460 & 2.358 \\
\hline \multicolumn{8}{|l|}{ F statistic } \\
\hline$F$ test excluded & $15.06^{* * *}$ & $14.43 * * *$ & $15.29^{* * *}$ & $12.94 * * *$ & $10.21^{* * *}$ & $10.02^{* * *}$ & $10.27^{* * *}$ \\
\hline \multirow[t]{5}{*}{ instruments } & $(0.0000)$ & $(0.0000)$ & $(0.0000)$ & $(0.0000)$ & $(0.0000)$ & $(0.0000)$ & $(0.0000)$ \\
\hline & $6.71^{* * *}$ & $6.13^{* * *}$ & $5.76^{* * *}$ & $5.76^{* * *}$ & $6.81 * * *$ & $7.69 * * *$ & $8.04^{* * *}$ \\
\hline & $(0.0000)$ & $(0.0000)$ & $(0.0000)$ & $(0.0000)$ & $(0.0000)$ & $(0.0000)$ & $(0.0000)$ \\
\hline & $6.27^{* * *}$ & $6.41^{* * *}$ & $6.40^{* * *}$ & $7.90 * * *$ & $7.71^{* * *}$ & $7.56^{* * *}$ & $8.21 * * *$ \\
\hline & $(0.0000)$ & $(0.0000)$ & $(0.0000)$ & $(0.0000)$ & $(0.0000)$ & $(0.0000)$ & $(0.0000)$ \\
\hline
\end{tabular}

Robust Standard Errors within parentheses (* 10\%, ** 5\%, *** 1\%). 
As Table 5 shows, almost all estimates are jointly significant at 1\% and the instruments used are valid (as indicated by the Overidentification Hansen J Statistic) ${ }^{7}$, at least in the range between 5 and 8 minutes, where the p-value of the Overindentification Hansen J Statistic is between 0.5705 and 0.3338 . When the market is wider the validity of the instruments is smaller although the p-value is never below 0.05 . The $\mathrm{F}$ test of the first stage shows that instruments are jointly significant at $1 \%$, but the results of the Cragg-Donald Wald F statistic are not so positive. As shown in the above table this statistic show that our instruments are weak which could not partially solve the problem of endogeneity, causing an attenuation bias in our estimates. This attenuation bias suggest that the results presented should be understood as a lower bound estimate of the effect of the number of competitors and own brand petrol stations on price.

As expected, the effect of rivals on equilibrium prices is negative and statistically significant at $1 \%$ in most cases, and the effects range from 1.24 euro cents in the market of 5 minutes to 0.18 cents if we define the market in 15 minutes. Additionally, as the isochrones become larger the effect of an additional competitor weakens. This result shows that the effect of having a close competitor is greater than that of having a competitor located at a greater distance.

Additionally, having more same outlet brands in the vicinity has a positive and significant impact on prices, as suggested by the theoretical model in section 2 , but only after 8 minutes distance. As the number of own brand outlets in the vicinity increases, the greater is a brand's market power, and have a positive impact on the price equilibrium. We can also observe that the coefficients are not significant for the first 8 minutes of distance. The reduced variation that exists in the first minutes can explain this result, making our simulations more imprecise.

Using the estimates of the impact of rivals on equilibrium prices, we conduct the hypothetical monopolist test: we compute the likely mean increase in prices if a rival in a each isochrone merges with a hypothetical monopolist. Having defined our objective function, we can make the following estimation:

$$
h\left(N_{0}^{r}, N_{0}^{o}, N_{0}^{o 2}\right)=E\left(p \mid N_{0}^{r}, N_{0}^{o}, N_{0}^{o 2}\right)
$$

\footnotetext{
${ }^{7}$ For an in-depth analysis of instruments, see Staiger \& Stock (1997) and Stock \& Yogo (2002).
} 
We obtain our best price prediction if we convert all rival gas stations to same brand pumps:

$$
\hat{h}\left(N_{1}^{r}=0, N_{1}^{o}=N_{0}^{o}+N_{0}^{r}, N_{1}^{o 2}=N_{1}^{o} * N_{1}^{o}\right)
$$

In this way we can calculate the increase in prices when moving from the current balance to the hypothetical market monopolization when the market is defined in different forms:

$$
\Delta \hat{p}_{1}=\frac{\hat{h}\left(N_{1}^{r}=0, N_{1}^{o}=N_{0}^{o}+N_{0}^{r}, N_{1}^{o 2}=N_{1}^{o} * N_{1}^{o}\right)-p_{0}}{p_{0}}
$$

Table 6 shows the test results when simulating the prices under monopoly. Column 1 shows the average price in the market while column 2 shows the average price equilibrium if one firm monopolizes the market. In column 3 we show the effect of monopolization in percentage terms. It is clear that the market for which monopolization causes a Small $(5 \%)$ but Significant and Non-transitory Increase in Prices (SSNIP) is that defined by a five- to six-minute travel-time isochrone around each station. 
Table 6. Price increases made by the hypothetical monopolist with MDI as pricing

\begin{tabular}{|c|c|c|c|}
\hline Minutes & $\begin{array}{c}\text { P1 } \\
\text { Average } \\
\text { price } \\
\text { (cents Euro) }\end{array}$ & $\begin{array}{c}\text { P2 } \\
\text { Simulate } \\
\text { average price } \\
\text { (cents Euro) }\end{array}$ & $\begin{array}{c}(\mathrm{P} 2 / \mathrm{P} 1)-1=3 \\
\text { Relative price } \\
\text { effect of } \\
\text { monopolization } \\
(\%)\end{array}$ \\
\hline 1 & 46.70414 & 46.39005 & -0.7 \\
\hline 2 & 46.70414 & 48.12614 & 3.0 \\
\hline 3 & 46.70414 & 47.96809 & 2.7 \\
\hline 4 & 46.70414 & 47.37012 & 1.4 \\
\hline 5 & 46.70414 & 49.34349 & 5.7 \\
\hline 6 & 46.70414 & 49.16338 & 5.3 \\
\hline 7 & 46.70414 & 48.86589 & 4.6 \\
\hline 8 & 46.70414 & 48.84147 & 4.6 \\
\hline 9 & 46.70414 & 48.10535 & 3.0 \\
\hline 10 & 46.70414 & 48.17785 & 3.2 \\
\hline 11 & 46.70414 & 48.2289 & 3.3 \\
\hline 12 & 46.70414 & 48.17678 & 3.2 \\
\hline 13 & 46.70414 & 48.32711 & 3.5 \\
\hline 14 & 46.70414 & 48.1992 & 3.2 \\
\hline 15 & 46.70414 & 48.2785 & 3.4 \\
\hline
\end{tabular}

Graphs 1 and 2 show how the effect of monopolization weakens as the isochrone is extended, falling below the 5\% threshold recorded for a travel time of 5 and 6 minutes. 
Graph 1. Increase in prices by the hypothetical monopolist in cents Euro (€)

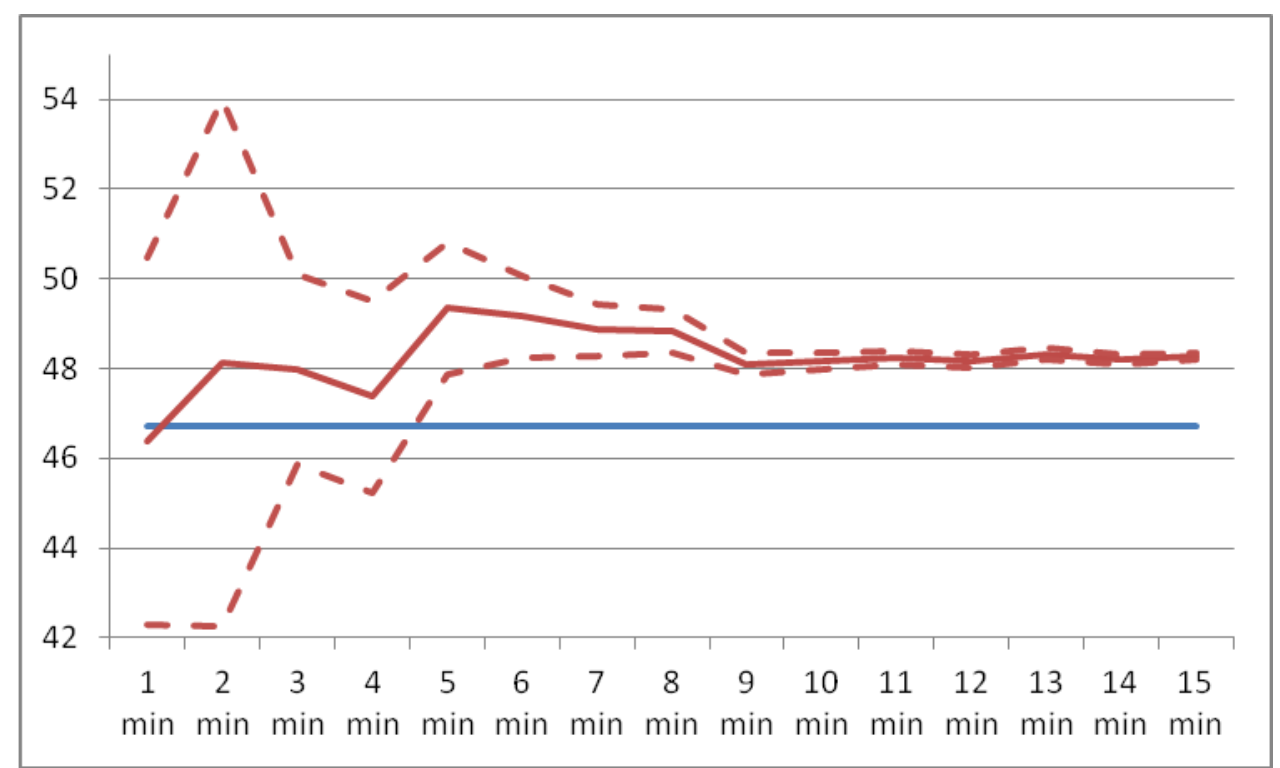

Graph 2. Percentage increase in prices by the hypothetical monopolist

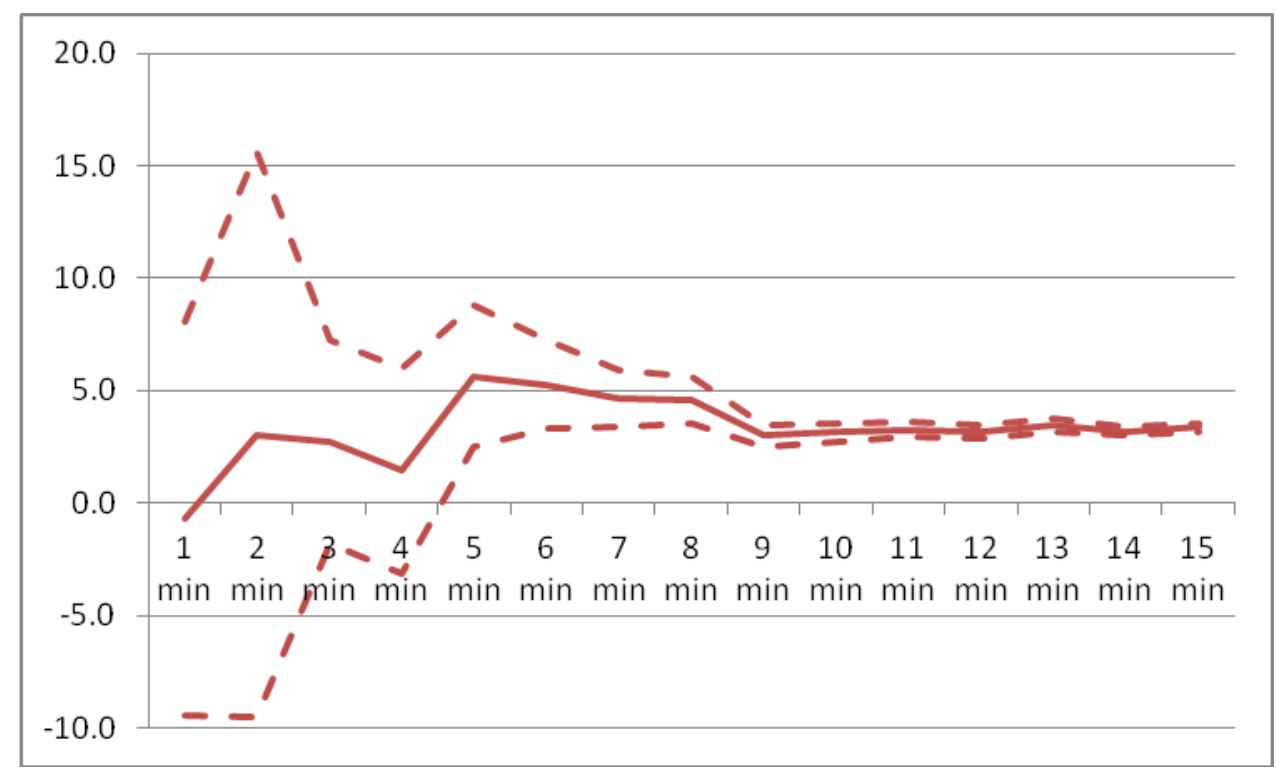

Regarding that the increase in prices generates an increase in profits and also that this increase will be "non-transitory", we must clarify two aspects.

It is true that we are assuming that the increase in prices will result in increased profits, so the monopolization of the market would bring no additional cost. This would make the 
monopolization of the market became profitable. We believe that there are not reasons to believe that the monopolization of the market will cause an increase in costs. Indeed it would be reasonable to think that increasing their market share even increase their purchasing power and costs could be reduced.

Regarding the change should be "non-transitory" we want highlight two aspects. On the supply side, when one brand monopolizes the market, there is not enough demand to allow entry of a new station. Even if increased demand enough to let a new operator, the time it takes to open a new service station is high, often exceeding one year. On the demand side, it is true that mobile apps and GPS allow information on fuel prices at an ever lower cost. However it should be noted that change the gas station to refuel not only have the cost of obtaining information to know which petrol is cheaper, but also has a cost of time, and therefore money, to travel to the cheapest gas station. This cost increases as additional displacement is greater, and can easily exceed the savings of refueling at a cheaper price. Therefore, the increase in prices that would occur when a brand monopolizes the market could be considered as "non-transitory"

This result has important policy implications both for the analysis of potential mergers and when implementing measures to promote competition.

When contemplating mergers, our results indicate that the relevant geographic market definition, which is essential to observe the evolution in concentration, must take into account the local nature of the gasoline retailing market. Traditionally, gasoline markets have been defined ad hoc, giving much larger market sizes than those indicated by the results reported here. An excessively broad definition of the relevant geographic market may mean the actual effects of a merger are not appreciated.

As for the measures to promote competition, these should impact the market structure within a five- to six-minute travel-time isochrone and not across the board. Two main measures can be implemented to boost competition: first, facilitating the entry of new operators, that is, of petrol brands other than those already established, within markets defined by a five- to six-minute isochrone. To facilitate this, potential barriers to entry in the market need to be identified and eliminated. Such entry would increase the number of rivals, which in turn would increase the level of competition and reduce the level of market prices. Second, measures are needed to facilitate the change of flag operators. If a market 
has more than one gas station under the same flag within the 5- to 6-minute isochrone, changing one flag would increase competition and reduce price levels.

In our empirical study of the 590 petrol stations comprising our sample, 228 do not have any competitor within a six-minute radius, which allows them to set significantly higher prices. The entry of new petrol stations of different flags, other than those already established, would increase competition and reduce the level of equilibrium prices. Among these 228 stations with no competitors, 114 stations have a petrol station of the same brand within this six-minute boundary. For these 114 petrol stations, changing the flag of one of them would bring about an increased level of competition and reduce the equilibrium price.

\section{Concluding remarks}

Geographic market definitions for merger and entry regulations tend to be too broad to take into account the fact that competition is only effective if outlets are located sufficiently close to each other. Traditional analyses of geographic markets have relied on techniques such as price correlations or chain of substitutions that are unable to identify how the interaction between outlets is eroded by distance.

We conclude that geographic information systems can be successfully employed in the precise definition of relevant geographic markets. In the case of petrol stations, we show that relevant markets are delineated by a five- to six-minute car travel-time isochrone centred on each petrol station. In each isochrone, it is easy to exert localised market power without competition. To drive competition in these local circumstances, markets need to be delineated on the basis of sufficiently small isochrones since only close rivals seem to compete effectively with each other.

This result should prove useful to policymakers. First, in contemplating merger cases, defining the relevant geographic market is crucial. An excessively narrow or broad definition of the market can mean significant effects are overlooked and wrong decisions might then be taken. Second, if the aim is to introduce measures to increase competition in the markets, then the local nature of competition between gas stations must be taken into consideration. Thus, we conclude that the elimination of potential entry barriers can facilitate the market entry of new operators at a distance defined by a car travel-time of five to six minutes. This would result in an increased level of competition and a reduction in the 
equilibrium prices, while measures designed to help retailers change brand would further add to the competition in the market.

\section{Acknowledgements}

Jordi Perdiguero thanks the funding received from Fundación Rafael del Pino and Joan Ramon Borrell thanks the funding received from the Catalan competition authority (Tribunal Català de Defensa de la Competencia, TDCD). Both authors thank the comments and suggestions from the members of the TCDC, the participants at the Encuentro de Economia Aplicada and EARIE 2007, and the funding received from RECERCAIXA. We thank the excellent research assistance in the use of geographic information systems by Adrià Botey. 


\section{References.}

Anderson S, de Palma A, Thisse J-F (1992) Discrete choice theory of product differentiation. The MIT Press, Massachusetts

Argentesi E, Ivaldi M (2007) Market Definition in the Printed Media Industry: Theory, Practice and Lessons for Broadcasting. In: Seabright P, Von Hagen J (eds) The Economic Regulation of Broadcasting Markets. Cambridge University Press, Cambridge, pp 225-252

Audy E, Erutku C (2005) Price test to define markets: an application to wholesale gasoline in Canada. J Ind Compet Trade 5:137-154

Bajari P, Hong H, Krainer J, Nekipelov D (2010) Estimating static games of strategic interaction. J Bus Econ Stat 28(4):469-489

Baker J (1999) Econometric Analysis in FTC vs. Staples. J Public Policy Mark 18:11-21

Berry S (1994) Estimating Discrete Choice Models of Product Differentiation. RAND J Econ 25(2):242-262.

Berry S, Levinsohn J, Pakes A (1995) Automobile Prices in Market Equilibrium. Econometrica 63:841-890.

Brenkers R, Verboven F (2006) Market Definition with Differentiated Products - Lessons from the Car Market. In: Choi JP (ed) Recent Developments in Antitrust: Theory and Evidence. The MIT Press, Massachusetts

Campbell JR, Hopenhayn HA (2005) Market size matters. J Indust Econ 53:1-25

Competition Commission (2003) Safeway plc and Asda Group Limited: A Report on the Mergers in Contemplation, September

Contin I, Correljé A, Huerta E (1998) Estrategias de Fijación de Precios en el Mercado Español de la Gasolina (1990-1997) Factores Explicativos. Econ Indus 321:35-46

Ivaldi M, Lörincz S (2011) Implementation Relevant Market Test: Application to Computer Servers. Rev Law Econ 7(1):31-73 
Office of Fair Trading (2005) Acquisition by Terra Firma Investments (GP) 2 Ltd of United Cinemas International (UK) Limited and Cinema International Corporation (UK) Limited

Pinkse J, Slade ME, Brett C (2002) Spatial price competition: a semiparametric approach. Econometrica 70:1111-1153

Sharma, K. (2011) SSNIP Test: A useful tool, not a panacea. Competition Law Reports $178: 188-192$

Spiller PT, Huang CF (1986) On the extent of the market: wholesale gasoline in the northeastern United States. J Indus Econ 35:131-145

Staiger D, Stock JH (1997) Instrumental variables regression with weak instruments. Econometrica 65:557-586

Stock JH, Yogo M (2002) Testing for Weak Instruments in Linear IV Regression. NBER Technical Working Paper Series, No. 284 


\section{Annex 1. Estimations with the variable number of rivals squared}

Table A1. IV estimates

$P_{i}=\alpha_{0}+\alpha_{1} N_{i}^{r}+\alpha_{2} N_{i}^{o}+\alpha_{3} N_{i}^{o 2}+\varepsilon_{i}$

Observations: 590

Endogenous regressor: $N_{i}^{r}, N_{i}^{r 2}, N_{i}^{o}, N_{i}^{o 2}$. Instruments: population, dummy brand of closest rival, MDI.

\begin{tabular}{|c|c|c|c|c|c|c|c|c|}
\hline & 1 minute & 2 minutes & 3 minutes & 4 minutes & 5 minutes & 6 minutes & 7 minutes & 8 minutes \\
\hline \multirow[t]{2}{*}{ Constant } & $45.931 * * *$ & $46.093^{* * *}$ & $46.265^{* * *}$ & $47.056^{* * *}$ & $46.539 * * *$ & $46.035^{* * *}$ & $46.071 * * *$ & $45.955^{* * *}$ \\
\hline & $(0.414)$ & $(0.406)$ & $(0.321)$ & $(0.000)$ & $(0.875)$ & $(0.753)$ & $(0.504)$ & $(0.502)$ \\
\hline N_rival(.) & (53.963) & $(5.570)$ & $(1.882)$ & $(1.431)$ & $(2.161)$ & $(1.215)$ & $(0.827)$ & $(0.612)$ \\
\hline N_rival(.) ${ }^{2}$ & -48.265 & -1.924 & 0.862 & 0.295 & 0.288 & 0.065 & -0.011 & -0.007 \\
\hline N_own(.) & $(4.036)$ & $(2.677)$ & $(1.476)$ & $(1.716)$ & $(1.747)$ & $(1.091)$ & $(0.916)$ & $(0.736)$ \\
\hline \multirow[t]{2}{*}{ N_own $(.)^{2}$} & 2.453 & -0.273 & 0.482 & 0.447 & 0.099 & -0.039 & -0.016 & -0.021 \\
\hline & $(4.590)$ & $(1.058)$ & $(0.540)$ & $(0.293)$ & $(0.252)$ & $(0.125)$ & $(0.097)$ & $(0.065)$ \\
\hline$F(4,172)$ & 1.52 & 0.71 & 1.78 & $2.58^{* *}$ & 1.44 & $2.30^{*}$ & $3.37 * *$ & $3.98^{* * *}$ \\
\hline Cragg-Donald Wald F & 0.144 & 0.441 & 0.332 & 0.261 & 0.321 & 0.725 & 0.297 & 0.169 \\
\hline
\end{tabular}


statistic

\begin{tabular}{lrrrrrrrr} 
F test excluded & $3.68^{* * *}$ & $4.49^{* * *}$ & $7.53^{* * *}$ & $9.55^{* * *}$ & $8.00^{* * *}$ & $8.43^{* * *}$ & $10.53^{* * *}$ & $10.89^{* * *}$ \\
instruments & $(0.0010)$ & $(0.0001)$ & $(0.0000)$ & $(0.0000)$ & $(0.0000)$ & $(0.0000)$ & $(0.0000)$ & $(0.0000)$ \\
& $3.38^{* * *}$ & $4.05^{* * *}$ & $2.44^{* *}$ & $5.82^{* * *}$ & $8.65^{* * *}$ & $9.78^{* * *}$ & $6.41^{* * *}$ & $9.05^{* * *}$ \\
& $(0.0021)$ & $(0.0004)$ & $(0.0208)$ & $(0.0000)$ & $(0.0000)$ & $(0.0000)$ & $(0.0000)$ & $(0.0000)$ \\
$2.53^{* *}$ & $3.74^{* * *}$ & $7.98^{* * *}$ & $8.24 * * *$ & $7.90^{* * *}$ & $7.05^{* * *}$ & $7.68^{* * *}$ & $7.62^{* * *}$ \\
& $(0.0168)$ & $(0.0009)$ & $(0.0000)$ & $(0.0000)$ & $(0.0000)$ & $(0.0000)$ & $(0.0000)$ & $(0.0000)$ \\
$2.02^{*}$ & $2.75^{* * *}$ & $7.29^{* * *}$ & $5.56^{* * *}$ & $6.22^{* * *}$ & $5.79 * * *$ & $5.33^{* * *}$ & $5.76^{* * *}$ \\
& $(0.0547)$ & $(0.0098)$ & $(0.0000)$ & $(0.0000)$ & $(0.0000)$ & $(0.0000)$ & $(0.0000)$ & $(0.0000)$ \\
\hline
\end{tabular}




\begin{tabular}{|c|c|c|c|c|c|c|c|}
\hline & 9 minutes & 10 minutes & 11 minutes & 12 minutes & 13 minutes & 14 minutes & 15 minutes \\
\hline \multirow[t]{2}{*}{ Constant } & $45.671 * * *$ & $45.749 * * *$ & $45.639 * * *$ & $45.739 * * *$ & $45.320 * * *$ & $45.666^{* * *}$ & $45.704 * * *$ \\
\hline & $(0.468)$ & $(0.568)$ & $(0.580)$ & $(0.587)$ & (0.804) & (0.691) & $(0.737)$ \\
\hline \multirow[t]{2}{*}{ N_rival(.) } & -0.365 & -0.217 & -0.335 & -0.143 & -0.304 & -0.400 & $-0.447 * *$ \\
\hline & $(0.364)$ & (0.391) & $(0.337)$ & $(0.378)$ & $(0.364)$ & $(0.259)$ & $(0.182)$ \\
\hline \multirow[t]{2}{*}{ N_rival(.) ${ }^{2}$} & 0.0001 & -0.010 & 0.003 & -0.008 & 0.003 & 0.010 & $0.012^{*}$ \\
\hline & $(0.037)$ & $(0.037)$ & $(0.026)$ & $(0.026)$ & $(0.021)$ & (0.013) & $(0.007)$ \\
\hline \multirow[t]{2}{*}{ N_own(.) } & $0.690 * *$ & $0.498^{*}$ & $0.542 * *$ & $0.441 * *$ & $0.524 * *$ & $0.449 * * *$ & $0.427 * * *$ \\
\hline & $(0.349)$ & $(0.302)$ & $(0.264)$ & $(0.226)$ & $(0.233)$ & (0.174) & $(0.146)$ \\
\hline \multirow[t]{2}{*}{ N_own(.) ${ }^{2}$} & -0.031 & -0.017 & -0.018 & -0.013 & $-0.014 *$ & $-0.011 * *$ & $-0.009 * *$ \\
\hline & $(0.027)$ & $(0.019)$ & $(0.014)$ & $(0.010)$ & (0.008) & (0.005) & (0.004) \\
\hline \multirow[t]{2}{*}{$F(4,172)$} & $6.19 * * *$ & $6.18^{* * *}$ & $6.36^{* * *}$ & $5.78^{* * *}$ & $4.17 * * *$ & $4.41 * * *$ & $4.08^{* * *}$ \\
\hline & (0.0001) & (0.0001) & $(0.0001)$ & $(0.0002)$ & $(0.0030)$ & $(0.0020)$ & $(0.0035)$ \\
\hline Overidentification & $7.879 * *$ & $9.126^{* *}$ & $7.415^{*}$ & $6.722 *$ & $7.986^{* *}$ & $6.691 *$ & 3.617 \\
\hline Hansen J Statistic & $(0.0486)$ & $(0.0277)$ & $(0.0598)$ & $(0.0813)$ & $(0.0463)$ & (0.0824) & $(0.3059)$ \\
\hline Cragg-Donald Wald & 0.396 & 0.634 & 0.610 & 0.526 & 0.610 & 0.684 & 1.226 \\
\hline \multicolumn{8}{|l|}{ F statistic } \\
\hline F test excluded & $15.06^{* * *}$ & $14.43 * * *$ & $15.29 * * *$ & $12.94 * * *$ & $10.21 * * *$ & $10.02 * * *$ & $10.27 * * *$ \\
\hline \multirow[t]{2}{*}{ instruments } & $(0.0000)$ & $(0.0000)$ & $(0.0000)$ & $(0.0000)$ & $(0.0000)$ & $(0.0000)$ & $(0.0000)$ \\
\hline & $17.95^{* * *}$ & 20.77 & $22.92^{* * *}$ & $18.27 * * *$ & $15.00 * * *$ & $14.60 * * *$ & $15.36^{* * *}$ \\
\hline
\end{tabular}




\begin{tabular}{lllllll}
$(0.0000)$ & $(0.0000)$ & $(0.0000)$ & $(0.0000)$ & $(0.0000)$ & $(0.0000)$ & $(0.0000)$ \\
$6.71^{* * *}$ & $6.13^{* * *}$ & $5.76^{* * *}$ & $5.76^{* * *}$ & $6.81 * * *$ & $7.69 * * *$ & $8.04 * * *$ \\
$(0.0000)$ & $(0.0000)$ & $(0.0000)$ & $(0.0000)$ & $(0.0000)$ & $(0.0000)$ & $(0.0000)$ \\
$6.27 * * *$ & $6.41^{* * *}$ & $6.40^{* * *}$ & $7.90^{* * *}$ & $7.71 * * *$ & $7.56 * * *$ & $8.21 * * *$ \\
$(0.0000)$ & $(0.0000)$ & $(0.0000)$ & $(0.0000)$ & $(0.0000)$ & $(0.0000)$ & $(0.0000)$ \\
\hline
\end{tabular}

Robust Standard Errors within parentheses (* 10\%, ** 5\%, *** 1\%). 